\title{
高定向石墨块的控制制备及其导热性能影响因素研究
}

\author{
袁观明 ${ }^{1}$, 薛 政 ${ }^{1}$, 崔正威 ${ }^{1}$, 董志军 ${ }^{1}$, 李轩科 ${ }^{1}$, 张中伟 ${ }^{2}$, 王俊山 ${ }^{2}$
}

(1. 武汉科技大学 省部共建耐火材料与冶金国家重点实验室, 武汉 430081; 2. 航天材料及工艺研究所, 北京 100076)

摘 要: 以廉价易得的高结晶度天然鳞片石墨 $(\mathrm{NG})$ 和中间相沥青为原料, 采用中温热模压一次成型再高温炭化、石 墨化处理可以制备高密度、高定向、高导热石墨块体材料。XRD、SEM 和 PLM 分析表明该石墨块具有高度择优 取向结构, 其内部石墨片垂直热压方向有序堆积排列。原料中鳞片石墨和沥青粘结剂的组成和配比以及制备工艺参 数等对所制石墨材料的面向导热性能有显著影响。采用 $86 \mathrm{wt} \%+32$ 目鳞片石墨和 $14 \mathrm{wt} \% \mathrm{AR}$ 中间相沥青在 $500^{\circ} \mathrm{C} 、$ $10 \mathrm{MPa}$ 下热模压成型的炭块经 $1000^{\circ} \mathrm{C}$ 炭化、 $2800^{\circ} \mathrm{C}$ 石墨化后样品的热物理综合性能较好，其体积密度达到 $1.91 \mathrm{~g} / \mathrm{m}^{3}$ 以上，室温面向热导率为 $550 \mathrm{~W} /(\mathrm{m} \cdot \mathrm{K}), 3000^{\circ} \mathrm{C}$ 石墨化室温面向热导率高达 $620 \mathrm{~W} /(\mathrm{m} \cdot \mathrm{K})$ 。

关 键 词: 石墨块; 高定向; 控制制备; 导热性能

中图分类号: TB303 文献标识码: A

\section{Controlled Preparation and Thermal Conductivity of Highly Oriented Graphite Blocks}

\author{
YUAN Guan-Ming ${ }^{1}$, XUE Zheng ${ }^{1}$, CUI Zheng-Wei ${ }^{1}$, DONG Zhi-Jun ${ }^{1}$, LI Xuan-Ke ${ }^{1}$, \\ ZHANG Zhong-Wei ${ }^{2}$, WANG Jun-Shan ${ }^{2}$
}

(1. Wuhan University of Science and Technology, The State Key Laboratory of Refractories and Metallurgy, Wuhan 430081, China; 2. Aerospace Research Institute of Materials and Processing Technology, Beijing 100076, China)

\begin{abstract}
Using cheap and available natural flake graphite with high crystallinity and mesophase pitch as raw materials, graphite block materials with high bulk density, highly preferred orientation and high thermal conductivity, were prepared by a hot-press molding at mild temperatures and subsequent carbonization and graphitization treatments at high temperatures. XRD, SEM and PLM analyses indicate that the prepared graphite block has a highly preferred structural orientation, the graphitic layers of the graphite flakes inside are clearly oriented perpendicular to the hot-pressing direction. The components of various sized flake graphite and different types of pitch binders, and the proportions of raw materials, as well as the preparation process parameters (including hot-pressing temperature and pressure, heat treatment temperature, etc.), have great influences on the room-temperature in-plane thermal conductivity of the resultant graphite blocks. Graphitized blocks prepared from 86wt\% NG (+32 mesh) and 14wt\% AR mesophase pitch through hot-pressed at $500^{\circ} \mathrm{C}$ at a fixed pressure of $10 \mathrm{MPa}$ for $5 \mathrm{~h}$ and subsequently underwent 1000 ${ }^{\circ} \mathrm{C}$ carbonization and $2800^{\circ} \mathrm{C}$ graphitization, have a good comprehensive thermophysical property. Their bulk density reaches above $1.91 \mathrm{~g} / \mathrm{m}^{3}$, and room-temperature in-plane thermal conductivity is measured as high as $550 \mathrm{~W} /(\mathrm{m} \cdot \mathrm{K})$, and improved to $620 \mathrm{~W} /(\mathrm{m} \cdot \mathrm{K})$ after $3000^{\circ} \mathrm{C}$ graphitization treatment.
\end{abstract}

收稿日期: 2016-08-29; 收到修改稿日期：2016-10-14

基金项目: 国家自然科学基金(91016003 \& 51372177); 湖北省教育厅科学研究计划(Q20141104) National Natural Science Foundation of China (91016003 \& 51372177); Hubei Provincial Department of Education Science Research Project (Q20141104)

作者简介: 袁观明(1978-), 男, 博士，副教授.E-mail: yuanguanming@wust.edu.cn

通讯作者: 李轩科, 教授. E-mail: xkli@21cn.com 
Key words: graphite block; high orientation; controlled preparation; thermal conductivity property

石墨材料具有耐高温、耐腐蚀、自润滑、抗热 震、导热及导电等优越性能，已经在航空、航天、 核工业、军工以及许多民用工业领域得到了广泛应 用。热物理性能是碳基功能材料的基本性质, 人们 对其已经有了较为充分的认识。在室温下, 石墨单 晶层面方向的理论热导率可达 $2000 \mathrm{~W} /(\mathrm{m} \cdot \mathrm{K})$ 以上 $^{[1]}$, 但是目前常用的石墨材料属于多晶无规取向材料, 其热导率较低, 一般仅为 70 150 W/(m·K $)^{[2]}$ 。因此, 对石墨材料导热性能(特别是定向导热)的研究及其 热管理领域的应用成为人们近期关注的焦点 ${ }^{[1-4]}$ 。

制备石墨材料的原料主要是碳质填料和粘结 剂。目前常用的填料有无烟煤、石油焦、沥青焦、 冶金焦、天然石墨和炭黑等。与石油焦和沥青焦类 填料相比, 天然鳞片石墨本身具有较高的石墨化 度、结晶取向度、热稳定性以及较低的电阻率和热 膨胀系数等诸多优点 ${ }^{[5-6]}$ 。另外, 我国的天然鳞片石 墨矿藏资源丰富, 而且价格低廉, 目前主要用于制 备石墨电极、柔性石墨以及石墨烯片等 ${ }^{[7-9]}$ 。近年来, 为了解决热管理领域面临的一些散热与导热问题, 人们纷纷尝试采用廉价的天然鳞片石墨为原料来制 备高导热石墨材料 ${ }^{[10-12]}$ 。与煤沥青、酚醛树脂等粘 结剂相比, 中间相沥青具有高纯度、高软化点和高 残炭率, 在高温热处理过程中很容易石墨化形成规 整的石墨结构 ${ }^{[13]}$, 因此作为粘结剂将有利于改善材 料的微观结构和导热性能。

本工作选用天然鳞片石墨和中间相沥青为原料, 采用特殊的混料工艺来实现物料的有效分散和均匀 混合, 即将沥青粘结剂均匀涂覆在鳞片石墨表面, 利用一次热压成型加高温热处理工艺制备高定向高 导热石墨材料, 并对其微观结构和物理性能进行表 征, 同时详细探讨原料组成和比例以及制备工艺等 对石墨材料导热性能的影响。

\section{1 实验方法}

\section{1 实验原料}

主要实验原料为山东天然石墨有限公司生产的 +32 目(篮上)天然鳞片石墨(纯度大于 $99.5 \%$ )。主要 采用的沥青粘结剂为日本三菱化学公司生产的萗系 中间相沥青(AR), 另外还选用了几种沥青进行对比 研究, 如武钢改质沥青“WG”, 实验室制备的萗沥 青“NP”和菜系中间相沥青“MP”，东岛碳素各向同
性煤沥青“SC”。

\section{2 制备方法}

采用球磨工艺将一定量的天然鳞片石墨和沥青 粘结剂粉料( $4 \mathrm{wt} \% \sim 18 \mathrm{wt} \%)$ 以及适量的有机溶剂分 散均匀后, 放入耐热不锈钢模具内进行热模压, 其 中热压温度约为 $500^{\circ} \mathrm{C}$, 热压压强约为 $10 \mathrm{MPa}$, 保 温恒压时间为 $5 \mathrm{~h}$, 冷却后即得热压炭块。再对热压 炭块进行高温炭化 $\left(1000 \sim 1500^{\circ} \mathrm{C}\right)$ 和石墨化 $(2800$ $\left.3000^{\circ} \mathrm{C}\right)$ 处理, 最终得到较低电阻率和较高热导率 的石墨材料。

\section{3 结构性能表征}

采用 Carl Zeiss AX10 型偏光显微镜和 NOVA400 NANO 型场发射扫描电子显微镜观察原料和不同石 墨材料的微观形貌和结构。采用 Philips $\chi^{\prime}$ PERT MPD PRO 型转靶 X 射线衍射仪对不同石墨样品进 行物相分析, 以 $\mathrm{CuK} \alpha$ 为辐射源, 并根据 Scherrer 和 Franklin 公式计算沥青炭和石墨材料的平均微晶尺 寸和石墨化度。采用四探针法利用 BS 407 型精密毫/ 微欧姆表测量不同石墨材料的室温电阻率。采用 LFA 457 Nanoflash TM 型激光热导仪测量石墨材料 的室温热扩散系数, 并计算其热导率。采用三点法 在 CMT4303 型微机控制电子万能试验机上测量不 同石墨材料的力学性能。

\section{2 结果与讨论}

\section{1 天然鳞片石墨涂覆沥青粘结剂}

天然鳞片石墨为片层状结构, 其表面十分光滑, 一般情况下与中间相沥青粘结剂不浸润、难相容, 很难实现二者的均匀混合。此外, 天然鳞片石墨的 石墨化度较高, 性质较脆, 在混料过程中很容易破 碎细化, 这样就破坏了鳞片石墨原有高取向结构, 因而不宜采用传统的热混捏、滚压和强力搅拌等工 艺来混合原料。

本研究添加适量的有机溶剂进行混磨, 再用低 温热处理脱除溶剂, 使沥青粘结剂均匀涂覆或包裏 在鳞片石墨表面, 如图 1(b)所示, 鳞片石墨表面均 匀涂覆了沥青粘结剂, 局部未涂覆沥青的区域在热 压成型过程中也会被熔融的沥青流动涂覆。涂覆沥 青的种类、用量及其性质是制备高定向高导热石墨 材料的关键。 

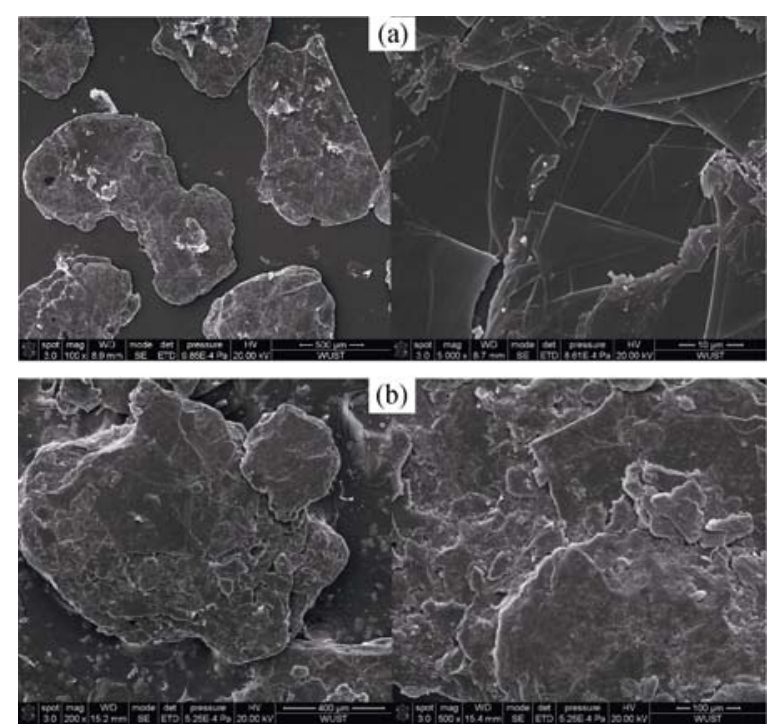

图 1 鳞片石墨涂覆沥青粘结剂(a)前(b)后的 SEM 照片

Fig. 1 SEM images of natural graphite flakes (a) before and (b) after coated by mesophase pitch binder

\section{2 高定向石墨块的形貌及织构}

图 2 为 $2800^{\circ} \mathrm{C}$ 石墨化样品的光学照片、理想堆 积织构和不同面的 XRD 图谱。从图 2(a)可以看出, 制备的石墨块样品纹理均匀、结构致密(体积密度高 达 $2.0 \mathrm{~g} / \mathrm{cm}^{3}$ ), 材料成型较好, 无明显裂纹和破损, 而且可以根据需要做成不同尺寸大小和厚度样品。

从图 2(b)石墨块样品内部石墨片的理想堆积织构示 意图中可以看出, 平面 $\mathrm{A}$ (热压面)上的鳞片石墨整 齐平铺于石墨块材主表面, 由中间相沥青相互粘结; 斜面 $\mathrm{B}$ 与平面 $\mathrm{A}$ 呈 $45^{\circ}$ 夹角; 侧面 $\mathrm{C}$ 即石墨块样品 的厚度面, 鳞片石墨一层层有序堆积、层叠排布, 切 口像整齐的累积书页。

以 $86 \mathrm{wt} \%+32$ 目鳞片石墨和 $14 \mathrm{wt} \%$ 中间相沥青 $\mathrm{AR}$ 为原料, 在 $500^{\circ} \mathrm{C} 、 10 \mathrm{MPa}$ 压强下制备的炭块经 $2800^{\circ} \mathrm{C}$ 石墨化所得石墨块不同面的 XRD 谱图如图 2(c)所示。石墨块 A 面与天然鳞片石墨原料具有相 同的 XRD 衍射峰, 但前者在 $2 \theta=26.5^{\circ}$ 附近的(002) 晶面衍射峰强于后者, 这是由于天然鳞片石墨经热 压成型处理后, 其片层的取向程度提高所致。石墨 块 C 面(002)晶面衍射峰非常弱, 其强度约为 A 面的 $1 / 1000$, 这说明鳞片石墨在石墨块中具有非常明显 的择优取向结构。Bacon ${ }^{[14]}$ 和 Tassone $\mathrm{e}^{[15]}$ 采用石墨块 体两个正交面(即 A 面和 C 面)(002) 晶面衍射峰强度 的比值来表征石墨材料的各向异性, 可见所制备的 石墨块具有类似定向热解炭(石墨)材料的高度各向 异性特征。除了(002)晶面衍射峰外, C 面还出现了 (100)、(101)、(110)等晶面衍射峰, 说明天然鳞片石 墨在石墨块中形成了三维层状堆积结构 ${ }^{[16-17]}$ 。当所
有的石墨片都如图 2(b)中所示那样高度定向堆积排 列形成理想取向结构时, XRD 谱图中(002)晶面衍射 峰将彻底消失 ${ }^{[18]}$ 。C 面较弱的(002)晶面峰可能与部 分鳞片石墨排列不理想有关或是存在少量的石墨碎 片以及沥青粘结剂高温热处理衍生的石墨颗粒, 因此出现较弱的(002)晶面衍射峰是很难避免的。B 面的衍射峰位置与 $\mathrm{C}$ 面相似, 其(002)晶面衍射峰 较强, 但比 A 面的稍弱一些; B 面的(101)和(103)晶 面衍射峰较强, 这与石墨微晶堆积排列择优取向 有关。

\section{3 高定向石墨块的微观结构}

图 3 为 $\mathrm{AR}$ 沥青粘结剂用量为 $14 \mathrm{wt} \%$ 样品 $2800^{\circ} \mathrm{C}$ 石墨化后不同面的 SEM 照片。从图 3(a)可以发现鳞 片石墨沿 A 面完全平铺, 这与图 1(a)单片鳞片石墨 表面的 SEM 像较为相似, 只有少量细石墨片微微 突起, 这可能与热压过程中这部分石墨片随沥青粘 结剂流动发生偏转或是在制样时因机械抛光打磨挂 起所致。图 3(b)显示 B 面呈阶梯状, 大部分鳞片石 墨断口整齐, 排布规整有序, 少量无序的细石墨片 可能与制样时机械切割打磨扰动有关。图 3(c)进一 步显示鳞片石墨几乎相互平行层叠堆积在一起, 形 成高度定向的三维石墨层状结构。图 3 中石墨块的 微观结构很好地验证了图 2(b)的堆积织构, 与图 2(c) 的 XRD 图谱地特征也相符。

从图 4 石墨块 $\mathrm{C}$ 面的偏光织构照片可以看出, 鳞片石墨沿垂直于热压方向堆积排列, 呈高度择优 取向状态。天然鳞片石墨片层间的中间相沥青粘结 剂呈线条状, 分布较为均匀, 经高温石墨化处理后 也呈择优取向。图 4 中黑色孔洞较少, 可能源于石 墨块原有孔隙或是制样时脱落的沥青炭空位, 孔洞 边缘处石墨片也具有较好的取向。

\section{4 高定向石墨块的物理性能}

$2800^{\circ} \mathrm{C}$ 石墨化样品的室温面向热导率高达 $552 \mathrm{~W} /(\mathrm{m} \cdot \mathrm{K})$, 而垂直方向 (沿厚度)的室温热导率 仅为 $25 \mathrm{~W} /(\mathrm{m} \cdot \mathrm{K})$, 两个正交方向上的热导率相差 22 倍, 说明所制备的石墨块具有较高的热学各向异性, 这是由石墨层片定向有序堆积排列形成的高度各 向异性结构决定的。石墨块的比热导率( 280)远高 于金属铜的比热导率( 44)。石墨块两个正交方向 的室温电阻率也明显不同, 分别为 $1.45 \mu \Omega \cdot \mathrm{m}$ 和 $8.35 \mu \Omega \cdot \mathrm{m}$, 相差 6 倍, 说明所制备的石墨块在电学 性能上也具有较高的各向异性，这源于石墨块结构 的各向异性。

采用天然鳞片石墨制备的石墨块力学性能不高, 也显示出一定的各向异性 ${ }^{[17]}$ 。 $1500^{\circ} \mathrm{C}$ 炭化样品的耐 


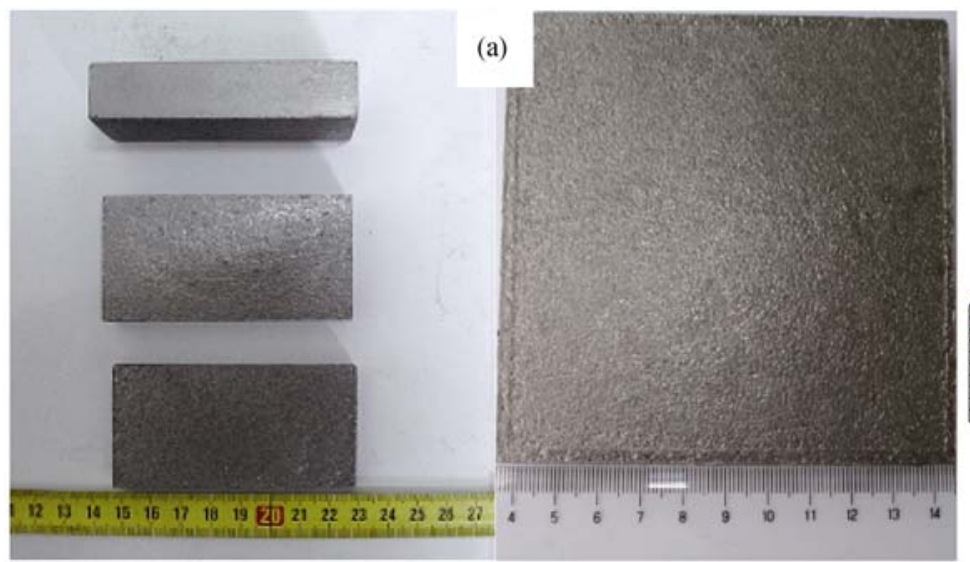

(b)
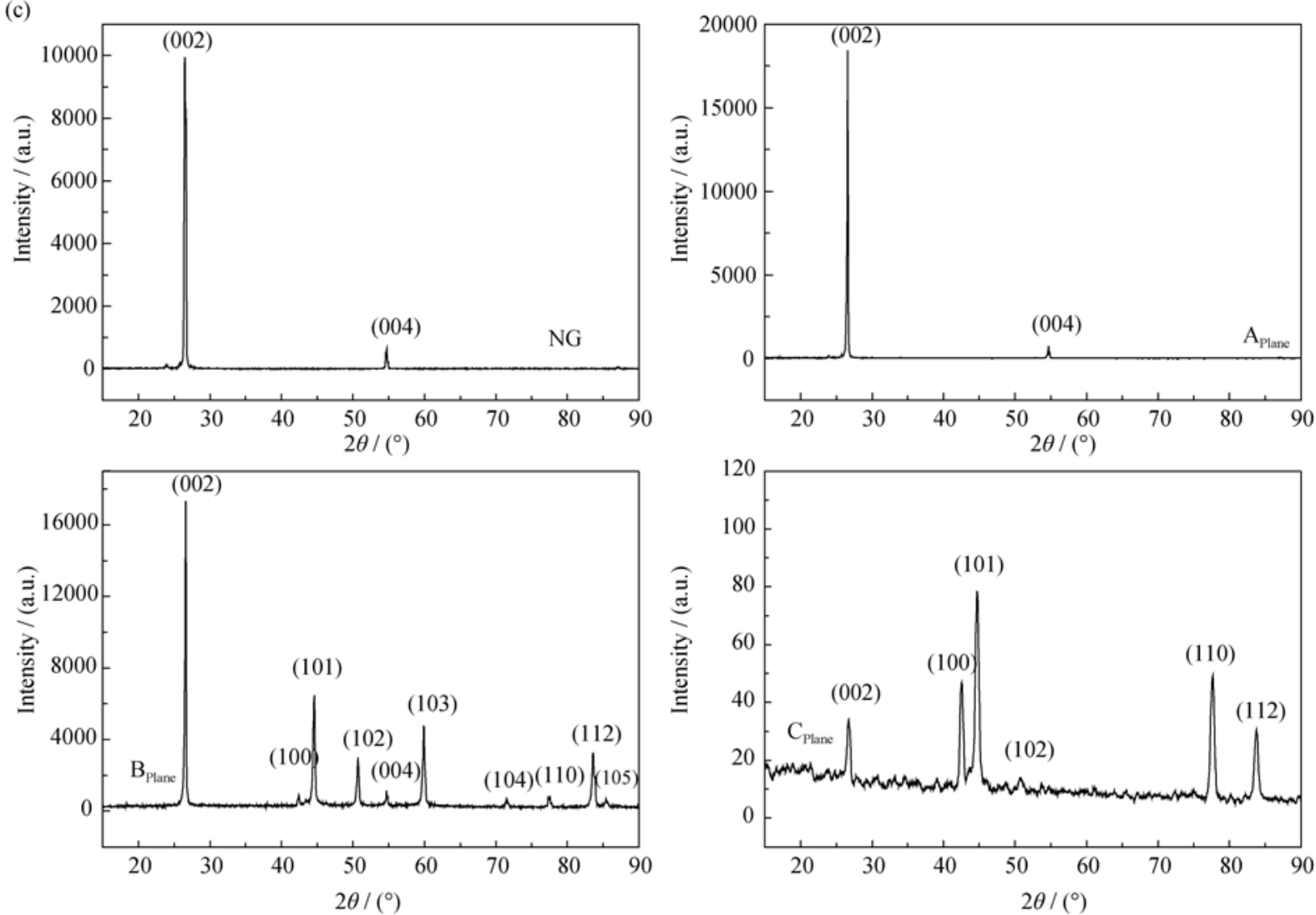

图 2 高定向石墨块 $2800^{\circ} \mathrm{C}$ 石墨化样品的(a)光学照片、(b)织构示意图及其(c)不同面的 XRD 谱图

Fig. 2 (a) Optical photos, (b) textural diagram and (c) XRD patterns of a highly oriented graphite block after heat treatment at $2800^{\circ} \mathrm{C}$

压强度在 10 15 $\mathrm{MPa}$ 之间, $2800^{\circ} \mathrm{C}$ 石墨化样品的耐 压强度在 $8 \sim 12 \mathrm{MPa}$ 之间。 $1500^{\circ} \mathrm{C}$ 炭化样品的抗弯 强度约为 7 12 $\mathrm{MPa}, 2800^{\circ} \mathrm{C}$ 石墨化样品的抗弯强度 约为 5 10 MPa。较低的力学性能与天然鳞片石墨自 身的脆性及其片层有序堆积形成的高度各向异性结 构有关。

\section{5 高定向石墨块导热性能的影响因素}

\subsection{1 沥青粘结剂种类及用量}

沥青粘结剂在制备石墨材料过程中起着非常重 要的作用, 能够涂覆鳞片石墨颗粒并把各种散料颗 粒粘结在一起, 填满内部空隙, 形成质地均匀且有
良好塑性的糊料, 以便在高温炭化过程中, 粘结剂 自身焦化形成粘结焦将散料颗粒结合成一个坚固的 整体，使材料制品具有所要求的机械强度和其它性 能。由图 1(b)可知沥青粘结剂涂覆或包裹在天然鳞 片石墨表面, 经高温炭化和石墨化处理后形成沥青 焦和石墨膜/颗粒，覆盖在天然鳞片石墨的表面并在 石墨制品中形成大量的表面/界面，这对炭(石墨)制 品的热传导性能影响很大。不同种类(性质)沥青粘 结剂形成的焦、炭和石墨具有不同的微晶组织和取 向，其微晶尺寸大小和石墨化度各不相同，因此会 对石墨材料的热传导性能产生很大影响 ${ }^{[19-20]}$ 。 

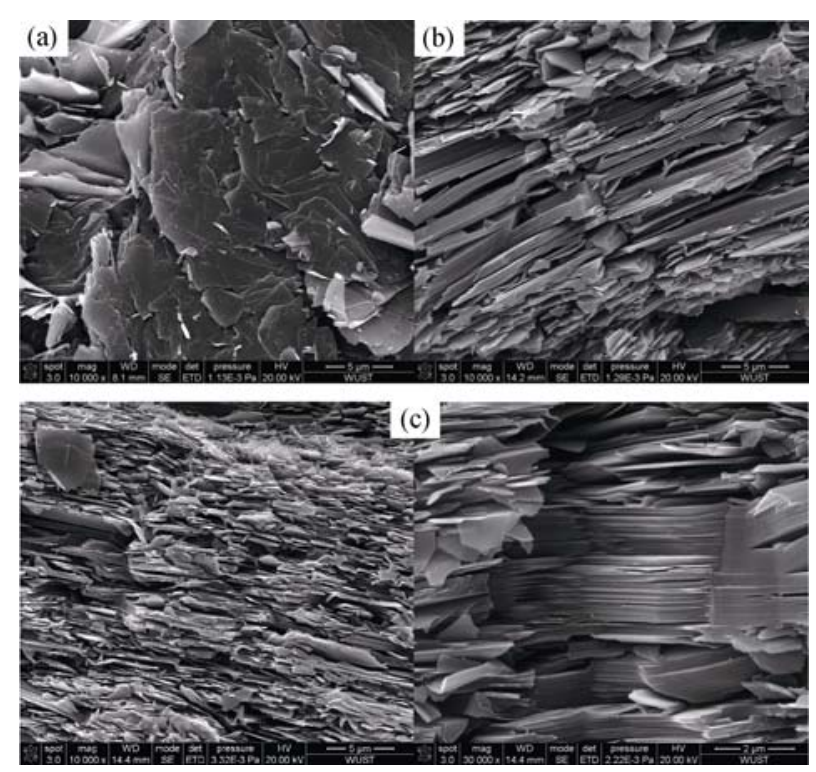

图 3 高定向石墨块 $2800^{\circ} \mathrm{C}$ 石墨化样品不同面的 SEM 照片 Fig. 3 Typical SEM images of a graphite block after heat treatment at $2800^{\circ} \mathrm{C}$ showing various planes (a-A, b-B, c-C)

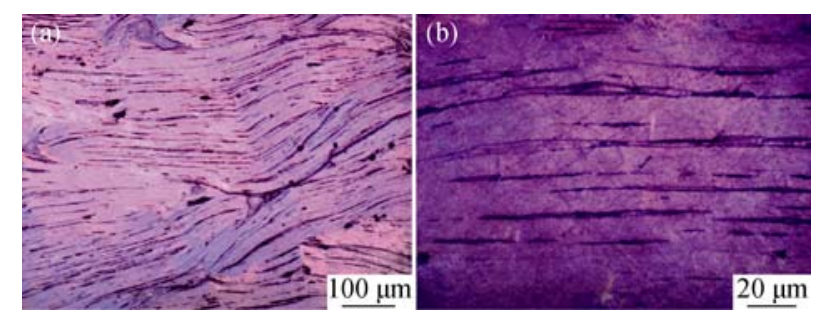

图 4 高定向石墨块 $2800^{\circ} \mathrm{C}$ 石墨化样品 $\mathrm{C}$ 面的偏光照片

Fig. 4 Typical PLM micrographs of graphite block after heat treatment at $2800^{\circ} \mathrm{C}$ showing the cross-section of side $\mathrm{C}$

表 1 是以 +32 目鳞片石墨和 $14 \mathrm{wt} \%$ 不同沥青粘 结剂为原料制备炭块样品 $2800^{\circ} \mathrm{C}$ 石墨化后的物理
性质, 从表中可以看出, 以武钢沥青 $\mathrm{WG}$ 和菜沥青 $\mathrm{NP}$ 为粘结剂制备的石墨块的体积密度较低, 这与沥青较 低的软化点和残炭率以及较高的挥发份(表 2)有关。这 两种石墨块室温面向电阻率较高、热扩散系数和热导 率较低, 除了与其体积密度较低有关外, 还与 WG 沥 青较高的灰分有关。以荟系中间相沥青 $\mathrm{MP}$ 和 $\mathrm{AR}$ 为 粘结剂制备的石墨块的体积密度较高, 这与该沥青较 高的软化点和残炭率以及较低的挥发份(表 2)有关。所 制石墨块室温面向电阻率较低、热扩散系数和热导率 较高, 除与其体积密度较高有关外, 还与沥青较低的 灰分密切相关。以 MP 沥青制备的石墨块的电阻率最 低, 为 $1.27 \mu \Omega \cdot \mathrm{m}$, 其室温面向热扩散系数和热导率 高达 $386 \mathrm{~mm}^{2} / \mathrm{s}$ 和 $530 \mathrm{~W} /(\mathrm{m} \cdot \mathrm{K})$, 比采用 $\mathrm{AR}$ 沥青作为 粘结剂所得石墨块略低一些, 这除与其体积密度稍低 有关以外，还可能与中间相沥青的灰分、光学织构及 其热态流动性能有关。以东岛碳素 SC 沥青为粘结剂 制备的石墨块的体积密度不高, 高温石墨化后沿块体 厚度方向有略微膨胀, 这可能与该沥青粘结剂的各向 同性结构和性质有关。但是所得石墨块室温面向电阻 率较低, 室温热扩散系数和热导率也较高。这说明以 高软化点和高残炭率沥青为粘结剂制备的石墨块传 导性能较好。这几种沥青原料 $2800^{\circ} \mathrm{C}$ 石墨化所得石墨 颗粒的微晶尺寸大小 $\left(L_{\mathrm{c}} 、 L_{\mathrm{a}}\right)$ 和石墨化度 $(g)$ 各不相同 (表 3), WG 沥青基石墨最小, SC 沥青基石墨其次, AR 沥青基石墨最大。沥青衍生的石墨颗粒的微晶尺寸大 小不同，其在石墨块体中形成的连结传导通道的完整 程度和择优取向程度可能也不同，因此会对石墨材料 的热传导产生截然不同的影响。沥青衍生石墨的微晶 尺寸越小, 其所得石墨块的热导率越低; 石墨微晶尺 寸越大, 其所得石墨块的热导率越高。

表 1 不同沥青粘结剂所制石墨块的物理性质

Table 1 Physical properties of graphite blocks made with different pitch binders

\begin{tabular}{ccccc}
\hline Pitch binder & $\rho /\left(\mathrm{g} \cdot \mathrm{cm}^{-3}\right)$ & $\sigma /(\mu \Omega \cdot \mathrm{m})$ & $\alpha /\left(\mathrm{mm}^{2} \cdot \mathrm{s}^{-1}\right)$ & $\lambda /\left(\mathrm{W} \cdot \mathrm{m}^{-1} \cdot \mathrm{K}^{-1}\right)$ \\
\hline WG & 1.76 & 2.02 & 294.01 & 388.1 \\
NP & 1.78 & 1.62 & 309.74 & 413.5 \\
MP & 1.83 & 1.27 & 385.66 & 529.3 \\
SC & 1.78 & 1.31 & 363.01 & 484.6 \\
AR & 1.91 & 1.45 & 395.52 & 551.6 \\
\hline
\end{tabular}

表 2 不同沥青粘结剂的基本物理性质

Table 2 Basic physical properties of different pitch binders

\begin{tabular}{ccccccc}
\hline Pitch binder & Softening point $/{ }^{\circ} \mathrm{C}$ & Ash content $/ \%$ & Volatile content $/ \%$ & Carbon yield $/ \%$ & $\mathrm{TI} / \%$ & $\mathrm{QI} / \%$ \\
\hline WG & 110 & 0.12 & 48.65 & 50.56 & 31.5 & 11.2 \\
NP & 82 & 0.004 & 55.31 & 44.65 & 1.3 & 1.0 \\
MP & 275 & 0.02 & 21.67 & 78.24 & 69.4 & 42.5 \\
SC & 280 & 0.03 & 19.52 & 80.25 & 67.8 & 20.6 \\
AR & 266 & 0.001 & 22.03 & 77.95 & 66.9 & 50.8 \\
\hline
\end{tabular}


表 3 不同沥青粘结剂 $2800{ }^{\circ} \mathrm{C}$ 石墨化后的微晶参数

Table 3 Microcrystal parameters of the different pitch binder-derived graphite particles after $2800{ }^{\circ} \mathrm{C}$ graphitization treatment

\begin{tabular}{ccccc}
\hline Pitch binder & $d_{002}$ & $L_{\mathrm{a}} / \mathrm{nm}$ & $L_{\mathrm{c}} / \mathrm{nm}$ & $g / \%$ \\
\hline WG & 0.3367 & 73.1 & 20.4 & 84.88 \\
NP & 0.3365 & 86.4 & 24.5 & 87.21 \\
MP & 0.3357 & 316.7 & 25.0 & 96.51 \\
SC & 0.3366 & 79.2 & 22.7 & 86.05 \\
AR & 0.3356 & 475 & 26.5 & 97.67 \\
\hline
\end{tabular}

5 种不同沥青经过 $2800^{\circ} \mathrm{C}$ 石墨化处理后得到的 石墨颗粒的偏光显微照片如图 5 所示, 从图中可以 看出, WG 沥青基石墨颗粒为细镶嵌结构, 石墨微晶 的尺寸较小, 其取向性较差, 因此以其作为粘结剂 制备的石墨块的热导率较低。NP 沥青基石墨颗粒为 粗镶嵌结构，部分区域出现明显取向结构，其石墨 微晶的大小和取向性明显提高, 这可能与沥青发生 聚合反应形成流线结构大分子有关，因此以其为粘 结剂制备的石墨块的热导率也有所增加。SC 沥青基 石墨颗粒以粗镶嵌结构为主，其石墨微晶尺寸虽然 较 WG 沥青大，但是晶体的取向度并不是很高，因 此以其为粘结剂制备的石墨块的热导率不是很高。 MP 沥青基石墨颗粒具有明显的长程微晶堆积和择 优取向结构, 其石墨微晶尺寸较大，沥青在熔融流 动过程中形成的石墨层片的取向程度较高, 这对制 备高导热石墨材料有利。特别是 AR 沥青在热处理
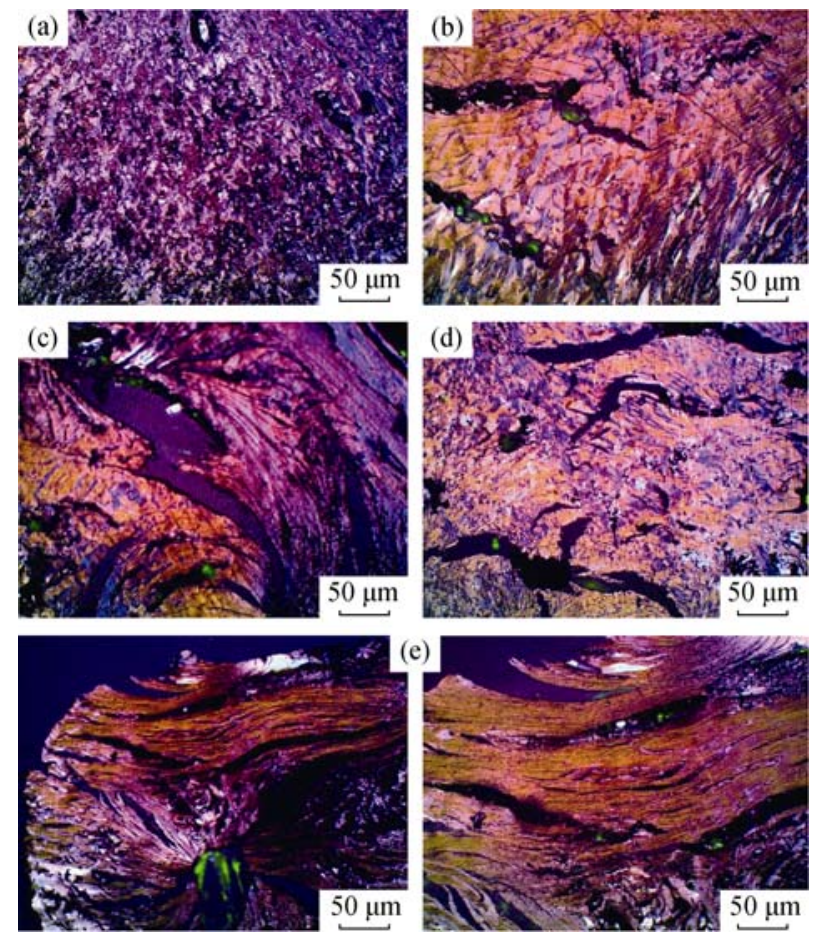

图 5 不同沥青粘结剂 $2800^{\circ} \mathrm{C}$ 石墨化后样品的偏光显微照片

Fig. 5 Typical PLM micrographs of different pitch binder-derived graphite particles after heat treatment at $2800^{\circ} \mathrm{C}$ a-WG; b-NP; c-MP; d-SC; e-AR
过程中形成的石墨颗粒具有明显的碳层堆积和长程 有序结构，其石墨晶体择优取向程度显著提高，石 墨微晶尺寸明显增加，因此以其为粘结剂制备的石 墨块的热导率最高。

以 +32 目鳞片石墨和不同用量 $\mathrm{AR}$ 沥青为原料 制备的炭块样品经 $2800^{\circ} \mathrm{C}$ 石墨化后的室温面向热 导率和热扩散系数如图 6 所示, 从图中可以看出, 石墨块样品室温热导率和热扩散系数均随沥青粘结 剂用量的增加而升高，直至沥青粘结剂的用量达到 $14 \mathrm{wt} \%$ ，超过此用量后样品的室温热导率和热扩散 系数稍微降低。

对高导热石墨块体而言, 对导热的贡献主要来 源于占绝大组分 $(82 \mathrm{wt} \%$ $96 \mathrm{wt} \%)$ 的鳞片石墨，中间 相沥青及其在随后热处理过程中形成的焦炭或石墨 起连结传导作用。如图 7 石墨块内部有序堆积的鳞 片石墨和沥青粘结剂衍生的石墨颗粒的理想堆积结 构所示，片层状鳞片石墨在模具内由于外力驱使和 熔融沥青粘结剂的流动作用而发生择优取向排列 (图 3、图 4), 石墨片堆积层之间的缝隙和颗粒之间 的间隙由沥青粘结剂来填补和粘结。对于同一粒度 的鳞片石墨, 其最紧密堆积排布所需要的中间相励

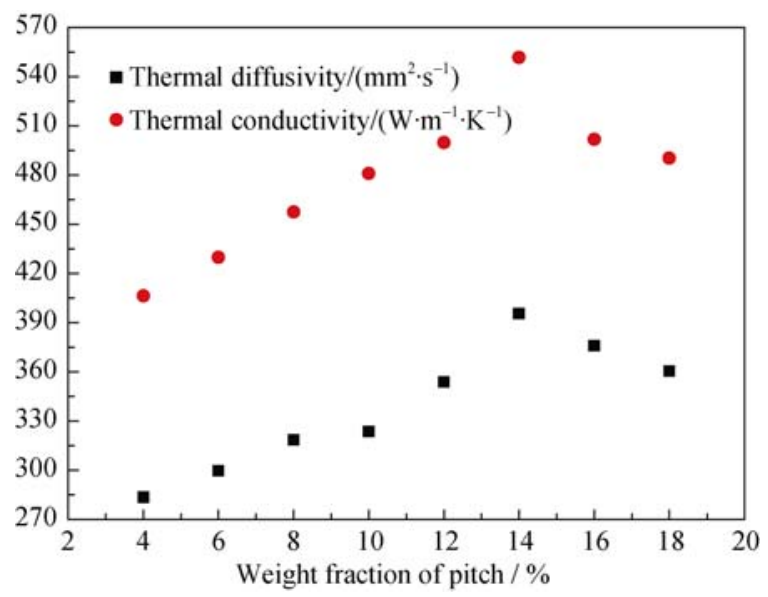

图 6 不同沥青用量样品 $2800^{\circ} \mathrm{C}$ 石墨化后的室温热导率和热 扩散系数

Fig. 6 Room-temperature thermal conductivity and thermal diffusivity of graphite blocks heat treated at $2800^{\circ} \mathrm{C}$ versus initial weight fraction of mesophase pitch 


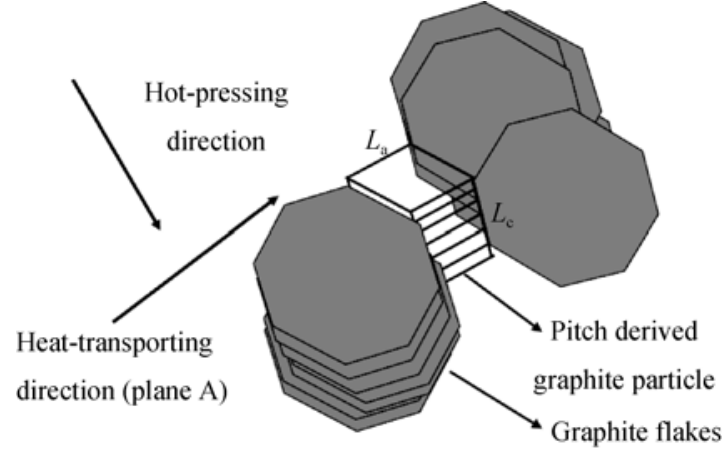

图 7 石墨块内部有序堆积的天然鳞片石墨和沥青粘结剂衍 生炭的理想结构

Fig. 7 Ideal structure of stacked natural graphite flakes and pitch binder derived carbon particles in a graphite block

青粘结剂的用量(充分浸润并涂覆，与其物理性质 密切相关)有一个较佳值(如 $14 \mathrm{wt} \%$ ), 低于或高于此 值均不能得到较高导热性能的石墨样品。沥青粘结 剂经高温石墨化处理形成有序程度不同(图 5)的炭 (石墨)颗粒, 其微晶尺寸 $\left(L_{\mathrm{c}} 、 L_{\mathrm{a}}\right)$ 的大小 (表 3)以及微 晶沿热传导方向的择优取向(图 7)程度决定了石墨 块内部导热通道的完整性和连续程度, 从而影响石 墨块的整体导热性能 ${ }^{[17]}$ 。因此选择纯度高、光学各 向异性发达、流线型织构、残炭率高, 而且熔融后 粘度小易流动取向、石墨化后微晶尺寸大、结构更 规整的中间相沥青作为粘结剂更有利于提高石墨材 料的热导性能。

\subsection{2 天然鳞片石墨纯度和粒度}

石墨块体的高导热主要来源于占绝大组分的鳞 片石墨, 因此鳞片石墨原料的纯度和粒度对其热导 率肯定有影响。将实验用天然鳞片石墨原料(纯度 $99.5 \%)$ 用氢氟酸浸泡处理后再进行水洗, 所制备的 石墨块室温面向热导率略微有所提高 $(10 \mathrm{~W} /(\mathrm{m} \cdot \mathrm{K})$, 约为 $2 \%$ ), 这主要是除去了影响热传导的一些微量 粉尘和矿物质(如氧化硅、氧化铁等)。但是采用氢 氟酸处理对设备要求高, 其制备工艺较复杂, 明显 增加了石墨材料的生产成本, 而且鳞片石墨在纯化 过程中容易破碎, 导致石墨块最终热导率提高不太 明显。

以不同粒度鳞片石墨和 $14 \mathrm{wt} \% \mathrm{AR}$ 沥青粘结剂 为原料制备的石墨块样品室温面向热扩散系数与热 导率如表 4 所示, 从表中可以看出, 石墨块样品的 室温热扩散系数与热导率随着鳞片石墨粒径的增大 而增加, 这是因为鳞片石墨自身具有片层状结构, 在热压过程中很容易沿垂直热压方向排列取向, 材 料的取向度越高, 晶格排列越规则, 对导热越有利, 其热导率就越高。鳞片石墨粒度越大, 其自身缺陷
表 4 不同粒度鳞片石墨所制石墨块样品室温 面向热扩散系数与热导率

Table 4 Room-temperature thermal diffusivity and thermal conductivity of graphite blocks prepared with different particle- sized graphite flakes

\begin{tabular}{ccccc}
\hline \multirow{2}{*}{$\begin{array}{c}\text { Thermal } \\
\text { property }\end{array}$} & \multicolumn{4}{c}{ Particle sizes of graphite flakes/ mesh } \\
\cline { 2 - 5 } & $80-40$ & $40-32$ & +32 & +20 \\
\hline$\alpha /\left(\mathrm{mm}^{2} \cdot \mathrm{s}^{-1}\right)$ & 343.8 & 360.8 & 395.5 & 366.1 \\
$\lambda /\left(\mathrm{W} \cdot \mathrm{m}^{-1} \cdot \mathrm{K}^{-1}\right)$ & 484.7 & 514.2 & 551.6 & 510.7 \\
\hline
\end{tabular}

越少，导热导电性能越好，而且择优取向的石墨层 片所占面积比例大，石墨片之间的界面缺陷少，晶 格波在石墨网平面内传播过程中发生散射的几率也 随之减弱 ${ }^{[5]}$, 因此以大粒径鳞片石墨为原料制备的 石墨块热导率较高。但是对于 +20 目的鳞片石墨制 备的石墨块, 其热扩散系数和热导率则出现了反常 现象，这是因为鳞片石墨的粒径太大很难与沥青粘 结剂混合均匀, 而且在混料过程中容易与陶瓷球碰 撞破碎细化，同时在热压成型过程中，太大粒径的 鳞片石墨可能会由于受力不均而发生变形破损。此 外, 大粒径天然鳞片石墨的比表面积较小, 达到最 紧密堆积理想状态所需要的沥青粘结剂的用量可能 低于 $14 \mathrm{wt} \%$, 较多的沥青粘结剂在块体内会发生团 聚，在随后高温热处理过程中沥青发生分解，以气 态形式挥发导致材料内部缺陷和孔隙增多, 导致石 墨块面向热扩散系数和热导率降低。

\subsection{3 热压成型温度和压力}

以+32 目天然鳞片石墨和 $14 \mathrm{wt} \% \mathrm{AR}$ 沥青为原 料, 在不同热压温度下(压力 $10 \mathrm{MPa}$ )制备的石墨块 物理性质如表 5 所列。从表 5 中可以看出: $300^{\circ} \mathrm{C}$ 热 压成型制备的炭块在随后高温热处理过程中因沥青 粘结剂的挥发分解而显著膨胀, 其体积密度较低, 石墨块内部孔隙率和缺陷较高, 因此室温热扩散系 数和热导率都比较低。500 ${ }^{\circ} \mathrm{C}$ 热压成型制备的石墨块 的体积密度较高, 其内部孔隙率和缺陷较低, 无序 排列堆叠的石墨组分也低, 因此室温热扩散系数和 热导率大大提高。这可能是由于 $500^{\circ} \mathrm{C}$ 热压处理后, 沥青已经完成半炭化过程, 形成了半焦或焦炭, 在 随后高温热处理过程中基本上不再挥发分解或分解 很少 ${ }^{[19]}$, 因此所得石墨块的体积密度变化较小, 其 内部石墨片取向结构发生紊乱的因素减少。进一步 提高热压成型温度至 $650^{\circ} \mathrm{C}$, 沥青粘结剂在压力作 用下完全炭化，在随后高温热处理过程中对材料内 部结构的影响较小, 因此所得石墨块室温面向热扩 散系数和热导率进一步提高, 但是 $650^{\circ} \mathrm{C}$ 高温热压 对实验设备要求较高。 
表 5 热压成型温度对所得石墨块物理性质的影响

Table 5 Influence of hot-pressing temperature on the physical properties of graphite blocks

\begin{tabular}{cccc}
\hline $\begin{array}{c}\text { Hot-pressing } \\
\text { temperature } /{ }^{\circ} \mathrm{C}\end{array}$ & $\rho /\left(\mathrm{g} \cdot \mathrm{cm}^{-3}\right)$ & $\alpha /\left(\mathrm{mm}^{2} \cdot \mathrm{s}^{-1}\right)$ & $\lambda /\left(\mathrm{W} \cdot \mathrm{m}^{-1} \cdot \mathrm{K}^{-1}\right)$ \\
\hline 300 & 1.66 & 331.36 & 412.5 \\
500 & 1.91 & 395.52 & 551.6 \\
650 & 1.95 & 415.13 & 607.1 \\
\hline
\end{tabular}

恒定热压温度为 $500^{\circ} \mathrm{C}$, 对热压压强(4 12 $\left.\mathrm{MPa}\right)$ 进行研究发现, 采用 $10 \mathrm{MPa}$ 压强制备的石墨块体 积密度 $\left(1.91 \sim 2.0 \mathrm{~g} / \mathrm{cm}^{3}\right)$ 较高, 其室温面向热导率也 高一些。材料成型密实化需要的压力与模具内中间 相沥青熔融后流动以均匀涂覆粘接石墨片需要的驱 动力和随后高温热处理过程中约束沥青挥发分解 “松弛”和材料体积膨胀的应力大小有关, 因此材料 密实化成型所需要的压力是有要求的。

\subsection{4 热处理温度}

从图 8 可以看出, 采用 $14 \mathrm{wt} \% \mathrm{AR}$ 沥青所制炭块 样品经不同温度 $\left(1000 \sim 3000^{\circ} \mathrm{C}\right)$ 炭化和石墨化处理 后，其室温面向热导率明显提高，这与中间相沥青 粘结剂在高温热处理过程中的结构演变有关，中间 相沥青是易石墨化原料, 由沥青焦向炭(石墨)转变 后其结构规整，层状堆积取向程度提高。同时，在石 墨化处理过程中，伴随着沥青炭碳网平面的生长、 发育, 产生或多或少的石墨叠层规整性 ${ }^{[19]}$, 从而显 著提高其热导率。 $3000^{\circ} \mathrm{C}$ 石墨化样品的室温面向热 导率高达 $622 \mathrm{~W} /(\mathrm{m} \cdot \mathrm{K})$ 。

\subsection{5 金属掺杂处理}

有研究报道在炭(石墨)材料中加入一些具有催化作 用的粒子(如 $\mathrm{Si} 、 \mathrm{Ti} 、 \mathrm{Zr}$ 等)可以显著提高石墨材料的热 导率。特别是中科院山西煤炭化学研究所刘占军等 $[2,10-11]$ 利用天然石墨、沥青和掺杂剂( $\mathrm{Si}$ 和 $\mathrm{Ti}$ 粉)为原料, 在

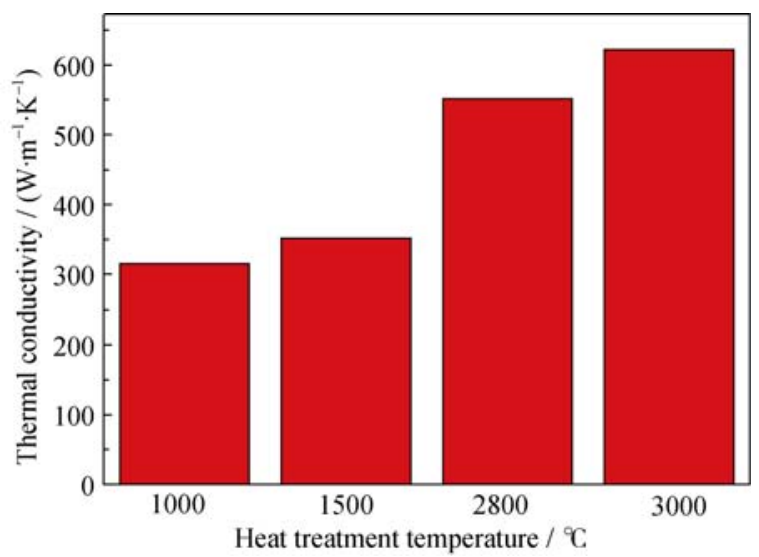

图 8 不同温度热处理石墨块的室温面内热导率

Fig. 8 Room-temperature thermal conductivity of graphite blocks versus heat treatment temperature
$2700 \sim 3000^{\circ} \mathrm{C}$ 高温下采用 $20 \sim 30 \mathrm{MPa}$ 压强热模压制备 掺杂石墨, 其室温面向热导率高达 456 704 W/(m·K), 较未掺杂纯石墨块的热导率 $(351 \mathrm{~W} /(\mathrm{m} \cdot \mathrm{K}))$ 明显提高。

本研究也采用 $\mathrm{Si} 、 \mathrm{Ti}$ 金属粒子对炭块分别进行 掺杂处理。在相同的工艺条件 $(+32$ 目鳞片石墨、 $14 \mathrm{wt} \% \mathrm{AR}$ 沥青粘结剂、 $500^{\circ} \mathrm{C}$ 热模压、10 MPa 压强 等)下所得 掺杂石墨块的物理性质如表 6 所示。从 表中可以看出：掺杂所得石墨制品体积密度较低, 这是因为掺杂后各组分之间的热膨胀系数不匹配 (金属的热膨胀系数明显高于石墨)以及在高温热处 理过程中形成的碳化物再分解导致石墨块的体积密 度下降。掺杂石墨块室温面向电阻率明显高于未掺 杂纯石墨块样品, 其热扩散系数和热导率明显低于 未掺杂样品。这与其体积密度降低、内部石墨层片 有序堆积结构发生变化有关，还与掺杂颗粒在材料 中产生点缺陷或是增加晶界引起声子散射而不利于 声子传播有关 ${ }^{[5]}$ 。

\section{6 高定向石墨块高温导热性能}

图 9 是以 $86 w t \%+32$ 目鳞片石墨和 $14 w t \% A R$ 励 青为原料制得的石墨样品不同温度下的比热容、热 扩散系数和热导率，从图中可以看出，随着测试温 度 $\left(25 \sim 1000^{\circ} \mathrm{C}\right)$ 不断升高, 石墨块的比热容逐渐增加, 最后趋于平稳; 石墨块的热扩散系数和热导率则随 着测试温度的升高而逐渐降低, 最后也趋于平缓。这 是由于炭(石墨)材料的热传导性能主要是靠晶格原 子的热振动而引起的。在一定温度下，晶体中原子的 热振动有一定的振幅。石墨晶体受热后, 其晶格点阵 的热振动加剧, 振幅增大, 声子运动的阻力也增强。 此外, 温度越高, 声子碰撞几率越大, 平均自由程越 短，相应热阻越大，即热导率越小 ${ }^{[5]}$, 所以材料的热 传导性能随测试温度的升高而下降。

与石墨材料的导热性能相似，传统金属材料 (如铜)的热导率也随测试环境温度的升高而明显降 低，虽然下降幅度不是很大，但是如果在空气气氛 中或有氧环境下，金属会随温度的升高而显著发生 氧化形成热导率非常低的氧化物，因此金属应用的

表 6 掺杂金属前后石墨块的物理性质

Table 6 Physical properties of $2800^{\circ} \mathrm{C}$ treated graphite blocks before and after doping

\begin{tabular}{ccccc}
\hline Dopants & $\rho /\left(\mathrm{g} \cdot \mathrm{cm}^{-3}\right)$ & $\sigma /(\mu \Omega \cdot \mathrm{m})$ & $\alpha /\left(\mathrm{mm}^{2} \cdot \mathrm{s}^{-1}\right)$ & $\lambda /\left(\mathrm{W} \cdot \mathrm{m}^{-1} \cdot \mathrm{K}^{-1}\right)$ \\
\hline Undoped & 1.91 & 1.45 & 395.52 & 551.6 \\
$5 \mathrm{wt} \% \mathrm{Si}$ & 1.79 & 1.90 & 307.21 & 412.4 \\
$5 \mathrm{wt} \% \mathrm{Ti}$ & 1.89 & 1.52 & 296.60 & 420.4 \\
$3 \mathrm{wt} \% \mathrm{Si}+$ & 1.65 & 2.25 & 229.20 & 283.6 \\
$5 \mathrm{wt} \% \mathrm{Ti}$ & & & & \\
\hline
\end{tabular}


领域和环境受到了一定的限制。而石墨材料则不存 在此问题，在低于 $400^{\circ} \mathrm{C}$ 的有氧环境中依然可以使用， 特别是在集成电路、封装技术等微纳电子领域，电子 元器件的工作环境温度一般在 $50 \sim 100^{\circ} \mathrm{C}$ 内, 石墨材 料在此温度下具有高的热扩散系数和热导率 $\left(270 \sim 370 \mathrm{~mm}^{2} / \mathrm{s}\right.$ 和 570 600 W/(m·K)), 结合其低的热 膨胀系数和良好的热机械性能, 而且可以通过工艺控 制和结构设计得到定向(面向)导热(受另一方向导热 率不高限制, 作为三维体相导热材料可能存在不足) 的热管理器件, 石墨材料这些独一无二的热学特性决 定其在热管理领域中有望部分取代传统金属材料。

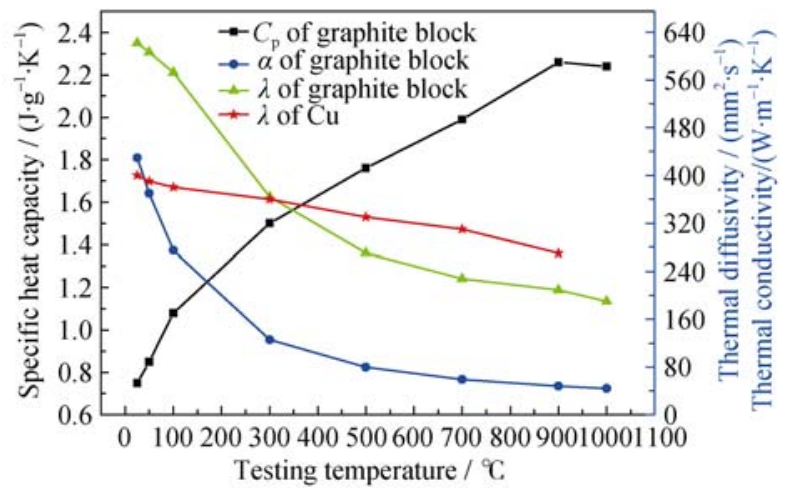

图 9 石墨块样品和纯铜的高温热学性质

Fig. 9 Thermophysical properties of graphite blocks and copper versus testing temperatures under non-oxygen atmosphere

\section{3 结论}

1) 以天然鳞片石墨和中间相沥青为原料, 采 用中等温度一次热压成型再经高温炭化、石墨化热 处理工艺可以控制制备高度择优取向的定向高导热 石墨块体材料。

2) 原料组成与配比(鳞片石墨的粒度/纯度、沥青 粘结剂的种类/性质及其用量/比例)和制备工艺(热压 成型条件、热处理温度、掺杂处理等)对所制石墨材料 导热性能有显著影响。以 $86 \mathrm{wt} \%+32$ 目鳞片石墨和 $14 \mathrm{wt} \% \mathrm{AR}$ 中间相沥青为原料, $500^{\circ} \mathrm{C} 、 10 \mathrm{MPa}$ 压强下 热模压成型的炭块经 $2800^{\circ} \mathrm{C}$ 石墨化后所得样品的热 物理综合性能(不考虑机械承载)较好, 其体积密度达 到 $1.91 \mathrm{~g} / \mathrm{m}^{3}$ 以上, 室温面向热导率高达 $550 \mathrm{~W} /(\mathrm{m} \cdot \mathrm{K})$, $3000^{\circ} \mathrm{C}$ 石墨化后进一步提高至 $620 \mathrm{~W} /(\mathrm{m} \cdot \mathrm{K})$, 石墨块 的室温面向电阻率降低至 $1.3 \mu \Omega \cdot \mathrm{m}$ 。

3) 该天然鳞片石墨基石墨块材料具有一定的 生产、加工和成本优势, 其高温热传导性能优于普 通金属, 加上石墨材料的本征特性, 有望在某些特
殊环境(如高温、腐蚀等)取代传统金属材料用作定 向导热、散热的热管理材料。

\section{参考文献:}

[1] NORLEY J. The role of natural graphite in electronics cooling. Electronics Cooling, 2001, 7: 50-51.

[2] QIU H P, SONG Y Z, LIU L, et al. Thermal conductivity and microstructure of Ti-doped graphite. Carbon, 2003, 41(5): 973-978.

[3] LUEDTKE A. Thermal management materials for high performance applications. Advanced Engineering Materials, 2004, 6(3): 142-144.

[4] ZWEBEN C. High-performance thermal management materials. Advanced Packaging, 2006, 15(2): 1-5.

[5] PIERSON H O. Handbook of Carbon, Diamond and Fullerenes. $1^{\text {st }}$ Edition. Park Ridge NJ: Noyes Publications, 1993: 50-67.

[6] KUGA Y, SHIRAHIGE M, FUJIMOTO T, et al. Production of natural graphite particles with high electrical conductivity by grinding in alcoholic vapors. Carbon, 2004, 42(2): 293-300.

[7] WANG H Y, YOSHIO M. Electrochemical performance of raw natural graphite flakes as an anode material for lithium-ion batteries at the elevated temperature. Materials Chemistry and Physics, 2003, 79(1): 76-80.

[8] BONNISSEL M, LUO L, TONDEUR D. Compacted exfoliated natural graphite as heat conduction medium. Carbon, 2001, 39(14): 2151-2161.

[9] GENG Y, WANG S J, KIM J K. Preparation of graphite nanoplatelets and graphene sheets. Journal of Colloid and Interface Science, 2009, 336(2): 592-598.

[10] LIU Z J, GUO Q G, SHI J L, et al. Preparation of doped graphite with high thermal conductivity by a liquid mixing process. Carbon, 2007, 45(9): 1914-1916.

[11] LIU Z J, GUO Q G, SHI J L, et al. Graphite blocks with high thermal conductivity derived from natural graphite flake. Carbon, 2008, 46(3): 414-421.

[12] PRIETO R, MOLINA J M, NARCISOA J, et al. Fabrication and properties of graphite flakes/metal composites for thermal management applications. Scripta Materialia, 2008, 59(1): 11-14.

[13] TAKAHASHI H, KURODA H, AKAMATU H. Correlation between stacking order and crystallite dimensions in carbons. Carbon, 1965, 2(4): 432-433.

[14] BACON G E. A method for determining the degree of orientation of graphite. Journal of Applied Chemistry, 1956, 6(11): 477-481.

[15] TASSONE G. Bacon anisotropy factor measurements on PyC by X-ray diffractometry. Carbon, 1970, 8(3): 387-388.

[16] FUJIMOTO H. Theoretical X-ray scattering intensity of carbons with turbostratic stacking and $\mathrm{AB}$ stacking structures. Carbon, 2003, 41(8): $1585-1592$.

[17] YUAN G M, LI X K, DONG Z J, et al. Graphite blocks with preferred orientation and high thermal conductivity. Carbon, 2012, 50(1): $175-182$.

[18] CHEN G H, WANG H Q, ZHAO W F. Fabrication of highly ordered polymer/graphite flake composite with eminent anisotropic electrical property. Polymer Advanced Technology, 2008, 19(8): 1113-1117.

[19] HORR N E, BOURGERETT E C, OBERLIN A. Mesophase powders (carbonization and graphitization). Carbon, 1994, 32(6): 1035-1044.

[20] MARSH H, MENENDEZ R. Carbons from pyrolysis of pitches, coals, and their blends. Fuel Process Technology, 1988, 20(1/2/3): 269-296. 